\title{
Commentary
}

\author{
Medications for Maintenance Treatment of Opioid Use Disorder in Adolescents: \\ A Narrative Review and Assessment of Clinical Benefits and Potential Risks, Offering a \\ Public Health Perspective-A Commentary on Camenga et al.
}

$\mathrm{T}_{\mathrm{pos}}^{\mathrm{n}}$ HE NARRATIVE REVIEW of clinical benefits and potential risks of medications for maintenance treatment of opioid use disorder (MOUD) among adolescents by Camenga and colleagues (2019 - this issue) is timely given the rising epidemiological trends of opioids (including opioid analgesics and heroin) among adolescents in the United States (Substance Abuse and Mental Health Services Administration, 2018). Currently, access to MOUD among adolescents with OUD has not been a readily available service option within systems of care (Hadland et al., 2017). This gap has been concerning not only because of increased opioid-related treatment admissions, emergency department visits, and accidental overdoses (National Academy of Sciences, Engineering, and Medicine, 2017) but also because of growing challenges with adolescent treatment effectiveness (Winters et al., 2014).

To date, much is known about promising behavioral approaches for addressing substance use disorders among adolescents, including motivational interviewing, familybased therapies, case management, and contingency management (Winters et al., 2014). However, research shows that despite benefits of behavioral treatments, relapse occurs within 1 year in more than half of the adolescents receiving treatment (Cornelius et al., 2003; Ramo \& Brown, 2008), suggesting the need for considering alternative strategies proven effective to treat substance use in adolescents. As such, the detailed synthesis of the evidence for MOUD for adolescent populations in the article is useful to the treatment community. However, given that the pharmacokinetic and pharmacodynamics properties of MOUD on adolescent neurobiology (positive and negative) is not fully understood (Hammond, 2016), questions remain.

Knowledge about the specific effects of MOUD on adolescent treatment outcomes when used in combination with other types of behavioral interventions is still lacking. An under-studied area that needs further attention, in particular, is the utility of MOUD in addressing outcomes related to adolescents with co-occurring opioid and other mental/physical health-related disorders, given that recovery for adolescents with co-occurring disorders is more complex because of the diverse risks of neuro-cognitive brain dysregulation
(Hanson et al., 2011). Therefore, future research is needed to understand not only the effects of MOUD on improving such neurological brain dysregulation (Fishman, 2015) but also how MOUD can, together with other behavioral and psychotropic medications, effectively address such neurobiological recovery challenges (Brewer et al., 2017).

Another area that needs attention with respect to the use of MOUD among adolescents is the overall diagnostic and clinical decision-making process. Currently, the standard for determining the extent to which an OUD is present is using the Diagnostic and Statistical Manual of Mental Disorders, Fifth Edition, which includes a set of 11 clinical criteria categorized around four areas linked to functional impairment, spanning self-control, role functioning, judgment, and physiology. According to assessment standards, individuals who meet at least 2 of 11 criteria during a 12-month period are diagnosed with a substance use disorder; severity ranges from mild, moderate, or severe based on the number of clinical symptoms present (American Psychiatric Association, 2013). To date, much of the evidence for MOUD efficacy and mechanisms of action has largely centered on addressing unique clinical features of OUD, including withdrawal and craving (U.S. Department of Health and Human Services, Office of the Surgeon General, 2018). However, when considering adolescent populations, it is important to expand beyond these specific clinical features associated with OUD, given their complex neurodevelopment (Koob et al., 2004; Squeglia \& Gray, 2016). Further, the signs and symptoms of OUD manifest differently in adolescents, with respect to withdrawal (Stewart \& Brown, 1995) and other social, physical, and psychological impairments (McGue \& Iacono, 2008).

Decades of developmental research shows that the period spanning adolescence is characterized by various events and life circumstances (Willoughby et al., 2013) that are associated with the severity and maintenance of drug use that need to be considered when making clinical treatment decisions (Tarter \& Horner, 2015). Hence, during assessment, it is important to consider the unique risk factors that have been identified to be associated with OUD severity among adolescents (Dennis \& Kaminer, 2006) and how they cor- 
relate with diagnostic-related OUD criteria-factors such as opioid consumption patterns and socio-emotional issues linked to opioid use, including physical problems (acute/ chronic pain), mental health disorders (depression/trauma), and environmental risk (access/availability, neighborhood insecurities, socioeconomic stress, and peer networks; Volkow et al., 2011). These complex risk factors should be considered when making clinical treatment decisions, because research with adolescents highlights how such risk factors influence not only the severity but also maintenance of drug use (Tarter \& Horner, 2015).

In an environment with emerging new medications, treatment options, and policies associated with MOUD aimed at enhancing the treatment service delivery system for OUD, the review by Camenga et al. (2019) is warranted. The article makes a significant contribution to the state of research knowledge on this topic for systems of care that serve adolescent opioid users. However, as the behavioral health service fields continue to move toward addressing access gaps to effective OUD treatment, more research is needed to inform responsive approaches that address developmental risk complexities of adolescent populations. In addition, more efforts are needed that focus on integrating MOUD training into the clinical SUD treatment workforce that covers adolescent components.

$$
\begin{array}{r}
\text { Rachel GonZales-CaStaneda, PH.D., M.P.H. }{ }^{a, b, *}, \\
\text { LARISSA J. MoOney, M.D. } .^{a, c} \\
\text { Richard A. RawsOn, PH.D. }{ }^{a, d}
\end{array}
$$

$$
\begin{array}{r}
{ }^{a} \text { Department of Psychiatry and Biobehavioral Sciences, } \\
\text { University of California, Los Angeles, } \\
\text { Los Angeles, California } \\
\text { 'Department of Psychology, } \\
\text { Azusa Pacific University, } \\
\text { Azusa, California }
\end{array}
$$

\section{${ }^{b}$ Department of Psychology, Azusa Pacific University, Azusa, California}

'Veterans Affairs Greater Los Angeles Healthcare System, Los Angeles, California

${ }^{d}$ Vermont Center for Behavior and Health, University of Vermont, Burlington, Vermont

\section{*rcastaneda@apu.edu}

\section{Conflict of Interest Statement}

The authors have no competing interests to declare.

\section{References}

American Psychiatric Association. (2013). Diagnostic and statistical manual of mental disorders (5th ed.). Arlington, VA: Author.
Brewer, S., Godley, M. D., \& Hulvershorn, L. A. (2017). Treating mental health and substance use disorders in adolescents: What is on the menu? Current Psychiatry Reports, 19, 5. doi:10.1007/s11920-017-0755-0

Camenga, D., Colon-Rivera, H., \& Muvvala, S. (2019). Medications for maintenance treatment of opioid use disorder in adolescents: A narrative review and assessment of clinical benefits and potential risks. Journal of Studies on Alcohol and Drugs, 80, 393-402. doi:10.15288/ jsad.2019.80.393

Cornelius, J. R., Maisto, S. A., Pollock, N. K., Martin, C. S., Salloum, I. M., Lynch, K. G., \& Clark, D. B. (2003). Rapid relapse generally follows treatment for substance use disorders among adolescents. Addictive Behaviors, 28, 381-386. doi:10.1016/S0306-4603(01)00247-7

Dennis, M. L., \& Kaminer, Y. (2006). Introduction to special issue on advances in the assessment and treatment of adolescent substance use disorders. American Journal on Addictions, 15, Supplement 1, 1-3. doi:10.1080/10550490601100619

Fishman, M. (2015). Relationship between SUD and psychiatric comorbidity: Implications for integrated health services. In Y. Kaminer (Ed.), Adolescent substance abuse and co-occurring disorders (pp. 21-48). Washington, DC: American Psychiatric Publishing.

Hadland, S. E., Wharam, J. F., Schuster, M. A., Zhang, F., Samet, J. H., \& Larochelle, M. R. (2017). Trends in receipt of buprenorphine and naltrexone for opioid use disorder among adolescents and young adults, 2001-2014. JAMA Pediatrics, 171, 747-755. doi:10.1001/ jamapediatrics.2017.0745

Hammond, C. J. (2016). The role of pharmacotherapy in the treatment of adolescent substance use disorders. Child and Adolescent Psychiatric Clinics of North America, 25, 685-711. doi:10.1016/j.chc.2016.05.004

Hanson, K. L., Cummins, K., Tapert, S. F., \& Brown, S. A. (2011). Changes in neuropsychological functioning over 10 years following adolescent substance abuse treatment. Psychology of Addictive Behaviors, 25, 127-142. doi:10.1037/a0022350

Koob, G. F., Ahmed, S. H., Boutrel, B., Chen, S. A., Kenny, P. J., Markou, A., ... Sanna, P. P. (2004). Neurobiological mechanisms in the transition from drug use to drug dependence. Neuroscience \& Biobehavioral Reviews, 27, 739-749. doi:10.1016/j.neubiorev.2003.11.007

McGue, M., \& Iacono, W. G. (2008). The adolescent origins of substance use disorders. International Journal of Methods in Psychiatric Research, 17, Supplement 1, S30-S38. doi:10.1002/mpr.242

National Academy of Sciences, Engineering, and Medicine. (2017). Pain management and the opioid epidemic: Balancing societal and individual benefits and risks of prescription opioid use. Washington, DC: National Academies Press. doi:10.17226/24781

Ramo, D. E., \& Brown, S. A. (2008). Classes of substance abuse relapse situations: A comparison of adolescents and adults. Psychology of Addictive Behaviors, 22, 372-379. doi:10.1037/0893-164X.22.3.372

Squeglia, L. M., \& Gray, K. M. (2016). Alcohol and drug use and the developing brain. Current Psychiatry Reports, 18, 46. doi:10.1007/ s11920-016-0689-y

Stewart, D. G., \& Brown, S. A. (1995). Withdrawal and dependency symptoms among adolescent alcohol and drug abusers. Addiction, 90, 627-635. doi:10.1111/j.1360-0443.1995.tb02201.x

Substance Abuse and Mental Health Services Administration. (2018). Key substance use and mental health indicators in the United States: Results from the 2017 National Survey on Drug Use and Health (HHS Publication No. SMA 18-5068, NSDUH Series H-53). Rockville, MD: Author.

Tarter, R. E., \& Horner, M. S. (2015). Developmental pathways to SUD and co-occurring psychiatric disorders in adolescents. In Y. Kaminer (Ed.), Adolescent substance abuse and co-occurring disorders (pp. 1-20). Washington, DC: American Psychiatric Publishing.

U.S. Department of Health and Human Services, Office of the Surgeon General. (2018). Facing addiction in America: The Surgeon General's spotlight on opioids. Washington, DC: Author. 
Volkow, N. D., McLellan, T. A., Cotto, J. H., Karithanom, M., \& Weiss, S. R. B. (2011). Characteristics of opioid prescriptions in 2009. JAMA, 305, 1299-1301. doi:10.1001/jama.2011.401

Willoughby, T., Good, M., Adachi, P. J., Hamza, C., \& Tavernier, R. (2013). Examining the link between adolescent brain development and risk tak- ing from a social-developmental perspective. Brain and Cognition, 83, 315-323. doi:10.1016/j.bandc.2013.09.008

Winters, K. C., Tanner-Smith, E. E., Bresani, E., \& Meyers, K. (2014). Current advances in treatment of adolescent drug use. Adolescent Health, Medicine and Therapeutics, 5, 199-210. doi:10.2147/AHMT.S48053 